\title{
Research on Callus Promotion and Protoplast Separate of Lavender Angustifolia
}

\author{
Miu Tianlin ${ }^{1, ~ a}$, Sunyanbin ${ }^{2, b}$, Ren Guoli ${ }^{2, ~ c}$, Xue Chunmei ${ }^{1, \mathrm{~d}, *}$ \\ ${ }^{1}$ Jiamusi University College of Life Sciences, Heilongjiang Province 154007, China \\ ${ }^{2}$ Jiamusi University College of Science, Heilongjiang Province 154007, China \\ a362227205@qq.com, b3145964@qq.com, ${ }^{c}$ chmqy215@163.com, \\ ${ }^{d, *}$ Corresponding Author:jmsxcm@126.com
}

Keywords: lavender angustifolia, protoplast separation, tissue culture, protoplast preparation

\begin{abstract}
To make a thorough inquiry about the optimum conditions for the separation of primary plastids from lavender-callus, providing basic data and theoretical basis for the optimization and breeding of lavender varieties. Using the lavender tender leaves as raw materials, the method of chemical induction was used to induce the dissociation of lavender to form the callus, which was used to dissociate the protoplast. The protoplast vitality was calculated with staining method. When cultured in MS medium with 2, 4-D $(1.8 \mathrm{mg} / \mathrm{L})$ and $6-\mathrm{BA}(0.5 \mathrm{mg} / \mathrm{L})$, lavender callus was the highest, up to $88 \%$; the content of callus in cellulase and pectinase were $1.8 \%$ and $0.5 \%$ under the conditions of enzymatic hydrolysis yield of protoplasts the highest, up to $1.180 \times 105$ per gram, the highest protoplast viability, induction conditions can reach $78.05 \%$. The efficient callus induced conditions of this experiment provide data support for further study of the subsequent callus regeneration system. The protoplast isolation system was established, and the protoplast of high yield and high vitality was obtained stably.
\end{abstract}

\section{Introduction}

Lavender angustifolia was a kind of perennial herb, native to the western Mediterranean ${ }^{[1]}$. It is widely used in medicine, food, oil making and other fields. It is an important chemical raw material with high economic value ${ }^{[2]}$. China's main plant lavender imported from abroad, because of the soil, soil property, climate and other factors lead to the seed germination rate is low, restricted the lavender industry's rapid development, therefore, lavender variety improvement and breeding optimization work is imminent. Because of the cells of callus and protoplast are of high potency , so they are the ideal experimental materials ${ }^{[3-5]}$, there are extensive applications in the study of plant variety improvement and cell physiology ${ }^{[6,7]}$. Exploring different concentration of growth regulator on the callus induction was the effect of different concentration of cell-wall degradation enzyme fluid and the effect of protoplast yield, etc. In order to optimize the lavender varieties, improve the adaptability of the northeast cold climate subsequent breeding work. The aim of this project is to establish the lavender breeding system, promote the development of lavender industry, replace traditional crop planting, and promote the transformation of agriculture model in northeast 
China to modern agriculture.

\section{Experimental Material}

\subsection{Experimental drugs}

MS medium, indolebutyric acid (IBA), 6-benzyl purine (6-ba), morpholine ethyl sulfonate (MES), mannitol, neutral red dye, NAA (NAA), 2, 4-dichloro-phenoxyacetic acid (2, 4-d).

\subsection{Experimental methods}

\subsubsection{Treatment of explants}

Choose lavender tender leaves as explants, flush with water for $20 \mathrm{~min}$, then foreign implant disinfection treatment in a sterile environment: with ethanol solution (75\%) were first surface disinfection $1 \mathrm{~min}$, sterile water flushing after five times, with a $0.1 \%$ mercuric chloride solution sterilization, sterile water wash 5 times.

Disinfection treatment after the explants is divided into 6 groups, each group of 50 strains of explants, and were given $3 \mathrm{~min}, 4 \mathrm{~min}, 5 \mathrm{~min}, 6 \mathrm{~min}, 7 \mathrm{~min}$ and $8 \mathrm{~min}$, sterilization time, explant treatment after transplantation in containing 6 - BA and NAA $(0.5 \mathrm{mg} / \mathrm{L})(0.1 \mathrm{mg} / \mathrm{L})$ on the MS culture medium of original culture, each earth bottle vaccination as a lavender explants, statistical explants survival rate after $18 \mathrm{~d}$, determine the best sterilization time. The results showed that the optimal sterilization time of the explants was $7 \mathrm{~min}$.

\subsubsection{Callus induction}

Lavender explants after processing the blade cut into the size of $0.5 \mathrm{~cm} \times 0.5 \mathrm{~cm}$ square, vaccination to induced medium containing different concentrations of plant growth regulator, each group of dealing with ten bottles of transplantation, each seed transplant five bottle lavender explants. To observe and record the induction of lavender callus, the rate of lavender was calculated after $25 \mathrm{~d}$.

\subsection{Separation of protoplast}

\subsubsection{Determine the osmotic pressure of lavender callus}

Configuration of mannitol solution of different concentration gradient, group number after in vitro, will receive after induction of lavender callus into containing different concentrations of mannitol solution in vitro, microscope after $1 \mathrm{~min}$ of callus plasmolysis condition to determine the osmotic pressure of lavender callus. The preliminary experimental results showed that the concentration of mannitol, suitable for lavender protoplast, was $0.6 \mathrm{~mol} / \mathrm{L}$.

\subsubsection{Separation and purification of protoplast}

In sterile environment callus with sterile forceps crush to $1 \mathrm{~mm}$ size, and then test materials will be prepared to 1:10 percentage in sterile triangle with enzymolysis liquid in the bottle, put triangle bottle at speed of $60 \mathrm{r} / \min 25{ }^{\circ} \mathrm{C}$ temperature table in the dark shocks digestion $12 \mathrm{~h}$ to free protoplast.

After enzymolysis fluid should be obtained in a sterile environment, first remove the slag quality through 200 mesh sieve, and low speed centrifuge centrifuge $8.0 \mathrm{~min}$ at a speed of $800 \mathrm{r} / \mathrm{min}$, abandon the supernatant, lower precipitation for coarse lavender protoplast. To join in the lavender 
protoplast of coarse extraction CPW lotion (0.1\% MES, $0.05 \mathrm{~mol} / \mathrm{LCaCl}_{2} \cdot 2 \mathrm{H}_{2} \mathrm{O}$ ), after repeated centrifugal 3 times, protoplast culture (MS liquid medium, $0.6 \mathrm{~mol} / \mathrm{L}$ mannitol) washing time, get the protoplast after purification.

\subsubsection{Production statistics and dynamic determination of protoplast}

The primary plastids after the statistical purification of the blood cell count board were used, and the number of samples in each group was counted 5 times. All data were processed with SPSS 16.60 , and the number of protoplast in each gram of cell was calculated $(1,2)$.

$$
\begin{gathered}
P=N \times 10 \times 100 \\
Y=\frac{P \times V}{M}
\end{gathered}
$$

In the formula: $\mathrm{P}$ is the protoplast number $(\mathrm{s} / \mathrm{mL})$ of the suspended liquid in each milliliter.

$\mathrm{N}$ is the primary mass number $(0.1 \mathrm{~mm} 2)$ in a large box.

$\mathrm{Y}$ is the production of protoplast (cuf/g).

$\mathrm{V}$ is the total volume of protoplast suspension (mL)

$\mathrm{M}$ is the fresh weight of suspended cells for enzymatic hydrolysis (g).

For dyeing method to determine the cell vitality, protoplast mix of neutral red dye solution and protoplast suspension dyeing, dye microscopy after $30 \mathrm{~s}$, are in good condition and energetic protoplast red, and each group of samples with blood count board statistics 5 times, calculate the protoplast vitality, as shown in formula (3).

$$
H=\frac{L}{T} \times 100 \%
$$

In the formula: $\mathrm{H}$ is means the vitality of protoplast (\%).

$\mathrm{L}$ is means the total number of protoplast in red.

$\mathrm{T}$ is means the total number of protoplast in observation.

\section{Results Analysis}

\subsection{The results of callus induction}

Table 1 The concentration of each component and the healing rate of the growth regulator

\begin{tabular}{cccc}
\hline Number & $2,4-\mathrm{D}(\mathrm{mg} / \mathrm{L})$ & 6-BA(mg/L) & Rate of callus(\%) \\
\hline 1 & 1.4 & 0.5 & $66 \pm 0.23$ \\
2 & 1.4 & 1.0 & $54 \pm 0.36$ \\
3 & 1.6 & 0.5 & $73 \pm 0.61$ \\
4 & 1.6 & 1.0 & $71 \pm 0.50$ \\
5 & 1.8 & 0.5 & $88 \pm 0.28$ \\
6 & 1.8 & 1.0 & $83 \pm 0.31$ \\
7 & 2.0 & 0.5 & $76 \pm 0.80$ \\
8 & 2.0 & 1.0 & $77 \pm 0.36$ \\
\hline
\end{tabular}

Callus induction results show that the number $1,2,3,4,5,6,7$ and 8 , callus of the healing rate was $66 \%, 54 \%, 73 \%, 71 \%, 88 \%, 83 \%, 76 \%$ and $77 \%$, the number 5 callus of the highest rates, number 2 the lowest rates of callus. Under the condition of invariable in 6 - the concentration of 
BA, 2, 4-d concentration increased from $1.4 \mathrm{mg} / \mathrm{L}$ to $1.8 \mathrm{mg} / \mathrm{L}$, callus of more rate increases, the 2, 4-d concentration increased from $1.8 \mathrm{mg} / \mathrm{L}$ to $2.0 \mathrm{mg} / \mathrm{L}$, the healing rate of callus is reduced, when visible growth regulator concentration is low, ACTS as a stimulus to the formation of callus induction and growth regulator in high concentration, the inhibition effect to the induction of callus formation, the results are shown in table 1.

\subsection{Protoplast separation}

Protoplast separation results show that in the case of pectinase content is $0.5 \%$, cellulose enzyme increased from $1.6 \%$ to $2.0 \%$, the content of protoplast yield and energy increases with the increase of content of cellulose enzyme; In the case of pectinase content is $1.0 \%$, cellulose enzyme increased from $1.6 \%$ to $1.8 \%$, the content of protoplast yield and energy increases with the increase of cellulose enzyme content, but the content of cellulose enzyme increased froml $1.8 \%$ to $2.0 \%$, makes the output of protoplast and vitality are declined, this phenomenon shows that high concentration of enzyme liquid, mixing of cellulase and pectinase enzyme liquid will also protoplast digestion, lose the cell vitality, the results are shown in table 2.

Table 2 Concentration of enzyme liquid, protoplast yield and vitality

\begin{tabular}{ccccc}
\hline Number & Cellulase (\%) & $\begin{array}{c}\text { Pecticenzym } \\
(\%)\end{array}$ & $\begin{array}{c}\text { Number } \\
10^{4}(\mathrm{cfu} / \mathrm{g})\end{array}$ & Energy (\%) \\
\hline 1 & 1.6 & 0.5 & $4.38 \pm 0.50$ & $73.14 \pm 0.82$ \\
2 & 1.6 & 1.0 & $7.78 \pm 0.23$ & $73.75 \pm 1.61$ \\
3 & 1.8 & 0.5 & $9.20 \pm 0.12$ & $75.56 \pm 0.55$ \\
4 & 1.8 & 1.0 & $11.80 \pm 0.54$ & $78.05 \pm 0.78$ \\
5 & 2.0 & 0.5 & $10.25 \pm 0.15$ & $75.13 \pm 0.43$ \\
6 & 2.0 & 1.0 & $11.03 \pm 0.33$ & $76.67 \pm 1.32$ \\
\hline
\end{tabular}

\section{Conclusions}

In this study, it was suitable for the induction medium of lavender callus: MS medium +2 , 4-d $1.8 \mathrm{mg} / \mathrm{L}+6$-BA $0.5 \mathrm{mg} / \mathrm{L}$, and the induction rate was $88 \%$. The ratio of enzyme liquid for the separation of the protoplast of lavender was: $1.8 \%$ of cellulose enzyme and $0.5 \%$ of pectin enzyme, and $1.180 \times 10^{5}$ protoplast yield and $78.05 \%$ energy. This study obtained the terms and conditions of the lavender callus induction and protoplast separation system is established, for subsequent get adapted to the northeast cold climate of lavender varieties breeding work to lay the foundation. But this experiment discussed the different concentration of growth regulator on the callus induction and the influence of different concentration of enzyme combination of protoplast separation effect, whether other factors on callus induction and lavender protoplast separation effect still needs further research.

\section{Acknowledgments}

Heilongjiang Provincial Nature Fund Project (C2017064); Heilongjiang College student’s innovation and entrepreneurship training program project: 201710222034.

\section{References}

[1] Kotsiris G, Nektarios P A, Paraskevopoulou A T. Lavandula angustifolia growth and physiology is affected by substrate type and depth when grown under Mediterranean semi-intensive green roof conditions [J]. HortScience, 2012, 47(2): 311-317. 
[2] Evans W C. Trease and Evans' Pharmacognosy E-Book [M]. Elsevier Health Sciences, 2009.

[3] Withers L A, Alderson P G. Plant Tissue Culture and Its Agricultural Applications: Proceedings of Previous Easter Schools in Agricultural Science, Published by Butterworths, London[M]. Butterworth-Heinemann, 2013.

[4] Huetteman C A, Preece J E. Thidiazuron: a potent cytokinin for woody plant tissue culture[J]. Plant cell, tissue and organ culture, 1993, 33(2): 105-119.

[5] Plant Tissue Culture and Its Bio-technological Application: Proceedings of the First International Congress on Medicinal Plant Research, Section B, Held at the University of Munich, Germany September 6-10, 1976[M]. Springer Science \& Business Media, 2012.

[6] Lusser M, Parisi C, Plan D, et al. Deployment of new biotechnologies in plant breeding[J]. Nature biotechnology, 2012, 30(3): 231-239.

[7] Zamir D. Improving plant breeding with exotic genetic libraries[J]. Nature reviews genetics, 2001, 2(12): 983-989. 